\title{
Confirmatory Factor Analysis of Industrial Inventory Management Optimization
}

\author{
RUNGROJ SUBANJUI $^{1 *}$, THANATCHAPORN THAWILPOL ${ }^{2}$ \\ ${ }^{1,2}$ Faculty of Business Administration \\ King Mongkut's University of Technology North Bangkok, Rayong Campus \\ 19 Moo 11 Nongrarok, Bankai, Rayong 21120 \\ THAILAND
}

\begin{abstract}
This research aimed to analyze the confirmatory factors and validate the compliance between the confirmatory factor structure of industrial inventory management optimization and empirical data. The sample were 500 industrial executives in Thailand. The research tool was a questionnaire, with a reliability value of 0.95. The data was analyzed with confirmatory factor analysis and second order confirmatory factor analysis. The results found that the factors of inventory management optimization comprised four factors based on the Deming Cycle, including Planning (Plan), Implementation (Do), Assessment (Check), and Improvement (Act). The findings of first order confirmatory factor analysis showed that all index values were over the criteria with a composition weight of $0.72-0.87$ at a statistical significance level of 0.01 . The second order confirmatory factor analysis showed that all index values were over the criteria with a composition weight of 0.86-0.91 at a statistical significance level of 0.01 . The model was congruent with the empirical data. The results of model validation indicated the $\mathrm{p}=0.46, \mathrm{CMIN} / \mathrm{DF}=0.99, \mathrm{GFI}=0.99$ and $\mathrm{RMSEA}=0.00$. The results of this research could be applied for further improvement of the efficiency of the organization's inventory management.
\end{abstract}

Key-words: industry, factors, confirmative component analysis, optimization, inventory management, deming cycle

Received: April 6, 2021. Revised: November 17, 2021. Accepted: December 1, 2021. Published: December 14, 2021.

\section{Introduction}

Today, running a business requires knowledge and competence to manage to be in sync with the rapidly changing and increasingly complex world. The business organization should be able to adapt to this circumstance and able to enhance quick response to the needs of customers. Such businesses are the ones who can withstand the ups and downs of the rapidly changing business world. Therefore, business practices must be planned and prudent. There should be a plan to determine the appropriate approach or strategy for the organization and various management optimizations from upstream to downstream even if the end result may be in the form of a product or service. A plan is essential to determine the strategy towards the perception of information, the approach towards inventory management or a detailed plan to reduce repetitive work processes in fields or departments of procurement, production, marketing, as well as research and development. Therefore, a plan to move forward strategically is essential to keep up with the competition and be able to meet the needs of customers in a timely manner whilst keeping in mind the competitors' capability. Inventory management; is a type of management that is essential for the development of the organization, with regards to storing components and products in the right place at the right time. Warehouse and inventory management within itself experience recurring problems in various industries with relation to supply chain. The continuous changes in the market have a direct impact on warehouse and inventory management, thereby, resulting in an excess of stock or the lack of stock [1]. If the inventory is managed effectively, the organizations are capable of avoiding the use of excessive storage capacity or shelf time for their products and components. Therefore, the importance of inventory management is to maintain excessive costs and create a financial advantage for the organization.

Warehouses are important in the industrial sector; they serve to store goods during the movement process. Furthermore, warehouses support the production and distribution of products to consumers in which logistics and supply chain 
processes are involved. Warehouses are spaces or locations to store products from the beginning of the supply process, on the way, or even at the end prior to reaching the consumer [2]. For a country in which the industrial sector is of great financial significance, warehouse management plays a key role in the development of the country. It is imperative that industry managers are encouraged to have the knowledge, understanding, and inventory management concepts to be used in the planning process.

'Business Process Improvement Strategy' is a strategy, used to analyse the procedures to identify the areas of improvement. Furthermore, to understand and maintain the standards that are required for the business. Thereby, invariably meeting the needs of the customers.

The most common problems that are a result of inefficient inventory management in the industrial sector are: Primarily, there is no inventory system or perhaps the inventory information is not recorded due to lack of accuracy in product counting. There is also a possibility of no documentation process or the lack of documentation during the inventory operations. Finally, there is also a possibility that the business lacks categorical storage of products [3].

From the study of, 'concepts to increase efficiency in inventory management', according to various principles; 'Continuous Improvement' of the work functions, to develop strategies that result in an increase in efficiency and reduce the cost of operations within the organization. The results of this research will be useful in the planning process for supply chain and inventory management. Further to manage industrial warehouse inventory maintenance and to be a guideline for improving and developing warehouses both within and without. In order to create efficiency in inventory management, the researcher is interested in finding factors that may increase the efficiency of inventory management in the industrial sector of Thailand by leading the Deming circuit. (Deming Cycle) These four elements are used as key components to determine the effectiveness of industrial inventory management. The reason being that the Deming cycle is a tool that consists of activities that help improve the organization by improving work efficiency [4]. The aim of this article is to analyze the confirmation factors for the optimization of inventory management in the industrial sector not only with respect to costs but also in regard to significant factors affecting the manage process. In regard to Deming Cycle, these factors are: plan, do, check and act. The results of this research could be applied for further improvement of the efficiency of the organization's inventory management.

\subsection{Research Objectives}

1) To analyze the confirmation factors for the optimization of inventory management in the industrial sector.

2) To examine the coherence between the corroborative structure of industrial inventory management optimization and empirical data.

\section{Literature Review}

\subsection{Deming Cycle}

The Deming Cycle, developed by William Edwards Deming, has been introduced to the Japanese industry since 1950 as a concept of basic quality improvement. It is the process to create an efficient production system in order to produce good quality products or services, it is also a concept applied to ensure a systematic work process [5].

Moen and Norman [6] summarized the components of the Deming cycle as follows:

1 . Plan $(\mathrm{P})$ is the planning process. To select problems, set goals, solve problems, and plan to solve them.

2. Do (D) is the procedure for solving the problems as planned.

3 . Check (C) is the process of checking and comparing the results for assess the alignment of actual action and plan.

4. Act (A) is to standardize and improve.

The Deming cycle is used to lead the implementation of problem solving, improvement, and development to achieve the intended goals.

Johnson [7] discusses the advantages of the Deming cycle:

1 . Implementing the Deming Cycle in the organization allows the practitioners to have a plan to prevent problems from occurring. Reduces confusion at work and further reduces the use of resources and raw materials. Thereby, reducing losses in various ways.

2 . The work is periodically inspected; therefore, it will make the operation concise and eliminate bottlenecks and issues before they arise.

3. Audits leading to improvements for issues that had already occurred and thereby ensuring it will not re-occur. Furthermore, to reduce the 
severity of the problem at hand, and careful plan steps to eliminate the issue.

4. Using the Deming Cycle to solve problems by 'Checking' and searching for the problem and the source of the problem. Understanding, when and why a problem occurs.

In short, with regards to the Deming cycle. It is a 4step process which consists of careful planning for systematic operations. To ensure that the planned operation coincides and is applicable to the various operations within the organization. If the intended plan yields good results, it can be classified as a standardized method. In the event that it does not go according to the specified plan, there must be reasoning and root cause analysis to understand the issues and bottlenecks within the plan. Further, if the plan is to be carried out, how should the problem at hand be solved? And set a plan for continuous rectification and improvement. However, for the Deming Cycle to be implemented and yield results all members within the organization must be involved in every step of the process.

\subsection{Inventory Management}

As inventory management is currently a topical issue, it has been addressed in many publications focusing on a variety of problems. It arises, in particular, from the need of enterprises for inventory management results to ensure certain market competitiveness. For instance, this matter is addressed by Atnafu and Balda [8] in their publication. They focused on small enterprises in Ethiopia and searched for empirical evidence in regard to inventory management that has a significant impact on the competitiveness of micro and small businesses. Inventory management efficiency is often measured through inventory management efficiency indicators. Specifically, it is the stock (inventory) turnover indicator that has been investigated in multiple publications. The research study [9] deals with an empirical analysis of the impact of demand uncertainty in the US retail sector on stock turnover performance. The issue of unequal customer demand in the context of inventory is very topical as well. This topic is addressed by authors in the literature [10], where they search for an answer to the question of whether the high and low inventory turnovers of retailers respond differently to demand shocks?

The impact of inventory management on overall supply chain performance is described by authors in publications. While literature [11] examines the impact of retailers with knowledge of supplier's inventory on supply chain performance, research study [12] investigates the effect of control system structure and the performance of an inventory goods flow system with long-variable delay. The interdependence among inventory types and firm performance is elaborated in publication [13].

The literature review conducted suggests that there are a number of research studies aimed at designing different inventory management models as well as evaluating inventory management performance. The objective of our manuscript is, based on a performed research study, to demonstrate the positive impact of a purposeful change in the objective function parameters on inventory management performance indicators.

\section{Research Methodology}

\subsection{Composition Synthesis}

The process of synthesizing the components of industrial inventory management optimization is as follows:

1. Study the documents, concepts, theories and research results related to the optimization of inventory management in the industrial sector.

2. Select the variables and elements related to the Deming Cycle, consisting of Planning, Doing, Evaluation (Check), and Correction (Act).

3. Apply the concept of the Deming Cycle as a research framework as shown in Fig. 1 by proposing a hypothetical model on the components of industrial inventory management optimization and consistent with empirical data.

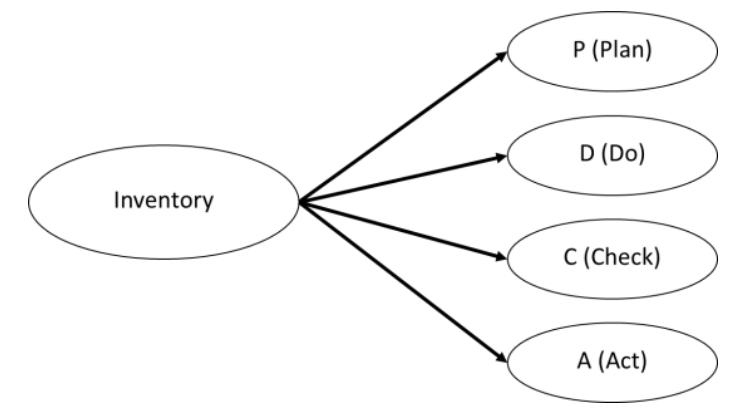

Fig. 1: Research Conceptual Framework

\subsection{Population and Sample}

The population used in this research were industrial executives in Thailand. There are a total of 70,410 sites [14]. The determination of the sample size was made by opening the appropriate sample size calculation table according to Taro Yamane's prefabricated table [15] at the level of 100 
confidence. 95 each with $\pm 5 \%$ error, a sample of 500 people was obtained using Probability Sampling by a Simple Random Sampling method.

\subsection{Research Tools}

The research instrument used was a questionnaire that was based on factors influencing the selection of electronic banking services in Rayong Province. The questionnaire had a rating scale, which included criteria for giving the weight of the assessment into 5 levels according to the Likert method, thereby allowing the respondents to make an appropriate choice [16]. The researcher presented the created draft questionnaire together with the assessment form to the experts who had knowledge and experience in the field, the experts considered a questionnaire of 3 persons to verify the quality of the tool by examining the consistency index between the questions and the research objectives. That is known as the (Index of ItemObjective Congruence: IOC) which is defined as the results of the examination of the consistency index between the questions and the research objectives. The value was between 0.60-1.00 and the optimal value should be 0.50 and above [17]. The researcher then used the questionnaire to implement with a population of 30 people with similar characteristics to the population in this study for analysis to determine the discriminant power. The questions are of a checklist format and the questions are based on a scale of estimation and approximation with a standard deviation (Standard Deviation: S.D.) Further, by analyzing the correlation coefficient (Correlation) to identify the confidence of the questionnaire. (Reliability) The discriminant power was between 0.43-1.84 and the reliability of the whole questionnaire was 0.95 , which is greater than 0.9 thereby proving that the confidence was at a high level [18]. Data was collected by asking the sample group permission participate and respond to the questionnaire.

\subsection{Data Analysis}

The researcher performed a factor analysis by calculating the correlation coefficient of each variable. Exploratory Factor Analysis (EFA) by Principal Component Method and Varimax Rotation. Generally, in a large sample correlations estimates are regarded as more reliable than in a small sample. Other EFA parameters crucial for the sample size is the magnitude of population correlations and number of factors of the estimated solution. The strongest the correlations and the fewer the factors the smaller the required sample [19]. Confirmatory Factor Analysis (CFA) and second order confirmation component analysis. Second-order Confirmatory Factor Analysis (SCFA) are placed in a hierarchy of factor analysis models, which shows how the fit of various models can be compared examines the coherence of the structure-correlation model of the components developed with the empirical data with the use of statistical and social science software packages.

\section{Results}

This research is a confirmation component analysis and examines the correspondence between the confirmation component structure, the confirmation component analysis of industrial inventory management optimization and the empirical data. The researcher divided the presentation of the research results as follows:

\subsection{The Results of Exploratory Factor Analysis (EFA)}

Exploratory Factor Analysis (EFA) was based on data from 30 items from a sample of 500 people. The procedural elements were extracted by Principal Component Analysis and sharply rotated the component axes by Varimax method.

The results of the analysis consider the element weight values, number of variables included in the measure and the variance of each element according to the criteria that can be determined in value of four components such as planning (Plan), implementation of the plan (Do), assessment (Check) and improvement (Act). Each factor must contain at least three items and the element must have a variance (Eigenvalues) greater than 1, the percentage of cumulative variance greater than $60 \%$, and the value of each variable in the component must have a factor loading of 0.3 or more [20] where each element is sorted by the sum of the variance in descending order. The results of an exploratory component analysis of industrial inventory management optimization: to identify 4 elements and name each element by considering the characteristics in which the variables align according to a conceptual framework and a theory. 
Table 1. Summarizes the results for an exploratory component analysis of industrial inventory management optimization.

\begin{tabular}{|l|c|c|c|c|}
\hline \multicolumn{1}{|c|}{ Element name } & $\begin{array}{c}\text { Variable } \\
\text { (items) }\end{array}$ & Eigenvalues & $\begin{array}{c}\text { percentage of } \\
\text { variance }\end{array}$ & $\begin{array}{c}\text { percentage of } \\
\text { cumulative } \\
\text { variance }\end{array}$ \\
\hline Element 1 Plan & 11 & 15.33 & 51.10 & 51.10 \\
\hline Element 2 Do & 6 & 1.84 & 6.15 & 57.25 \\
\hline Element 3 Check & 7 & 1.45 & 4.86 & 62.11 \\
\hline Element 4 Act & 6 & 1.01 & 3.37 & 65.48 \\
\hline \multicolumn{1}{|c|}{ total } & 30 & 19.63 & 65.48 & - \\
\hline
\end{tabular}

From Table 1, the summary of the survey results of the survey component analysis on the optimization of inventory management in the industrial sector consists of 11 items of planning, 6 items of implementation, 7 items of evaluation and 6 items of improvement. From the exploratory component analysis, it was found that none of the variables failed to meet the criteria for consideration. A total of 30 variables were over the criteria.

\subsection{The Results of the Corroborative Component Analysis}

At this stage of the research, the researcher used Factor Analysis (Exploratory Factor Analysis (EFA)) to categorize a large number of variables to create a research conceptual framework.
Exploratory factor analysis is also a technique or statistical tool used to reduce multiple variables. Complex variables are related to each other in an easy-to-understand format. (Confirmatory Factor Analysis (CFA)) was used to examine the structural validity of the observed variable measures in research and model development to be consistent with empirical data which is a model that the researcher continuously modified until deemed complete, acceptable and reliable according to the principles of the research process. Researchers need to take into account the criteria used to evaluate and modify the model, it must also be widely accepted and used. Arbuckle [21] recommends the model evaluation criteria that should be used. As shown in Table 2.

Table 2. Criteria for assessing the conformity of the underlying model with the empirical data.

\begin{tabular}{|l|c|l|}
\hline \multicolumn{1}{|c|}{ Evaluating the Data-Model Fit } & Criteria & \multicolumn{1}{c|}{ Consideration } \\
\hline 1) CMIN- $\rho$ : Chi-square Probability Level & $\rho>0.05$ & $\begin{array}{l}\text { The value } \rho \text { must be greater than } \\
0.05 . \\
\text { The higher the value } \rho \text {, the better. }\end{array}$ \\
\hline 2) CMIN/df : Relative Chi-square & $<3$ & $\begin{array}{l}\text { CMIN/df must be less than 3. } \\
\text { The closer the CMIN/df value is to } \\
0, \text { the better. }\end{array}$ \\
\hline 3) GFI : Goodness of fit Index & $>0.90$ & $\begin{array}{l}\text { The GFI must be greater than } 0.90 . \\
\text { The closer the GFI value to } 1, \text { the } \\
\text { better. }\end{array}$ \\
\hline 4) RMSEA : Root Mean Square Error of Approximation & $\begin{array}{l}\text { The RMSEA value must be less } \\
\text { than } 0.08 . \\
\text { The closer the RMSEA value is to } \\
0, \text { the better. }\end{array}$ \\
\hline
\end{tabular}

Table 2 shows the four key model assessment criteria of the AMOS program, which the researcher used to adjust the research model to meet all of the criteria. Therefore, it can be considered that the model is complete, acceptable and reliable in accordance with the principles of the research process.

The results of CFA were used to verify the structural validity of the gauge, prior to component modification revealed that $\mathrm{p}=0.00, \mathrm{CMIN} / \mathrm{DF}=$
4.74, GFI $=0.79$ and RMSEA $=0.08$, indicating that the model was inconsistent with the data empirical. The researcher adjusted the composition to choose a method to exclude observed variables that had inappropriate values. Further, connected the arrowhead so that the modified latent component or variable is most consistent with the empirical data. The results of the CFA verified that the structural validity of the gauge after component modification revealed that $\mathrm{p}=0.48, \mathrm{CMIN} / \mathrm{DF}=$ 
$0.95, \mathrm{GFI}=0.99$ and RMSEA $=0.00$, indicating that the model was in sync with the analytical data as shown in Fig. 2.

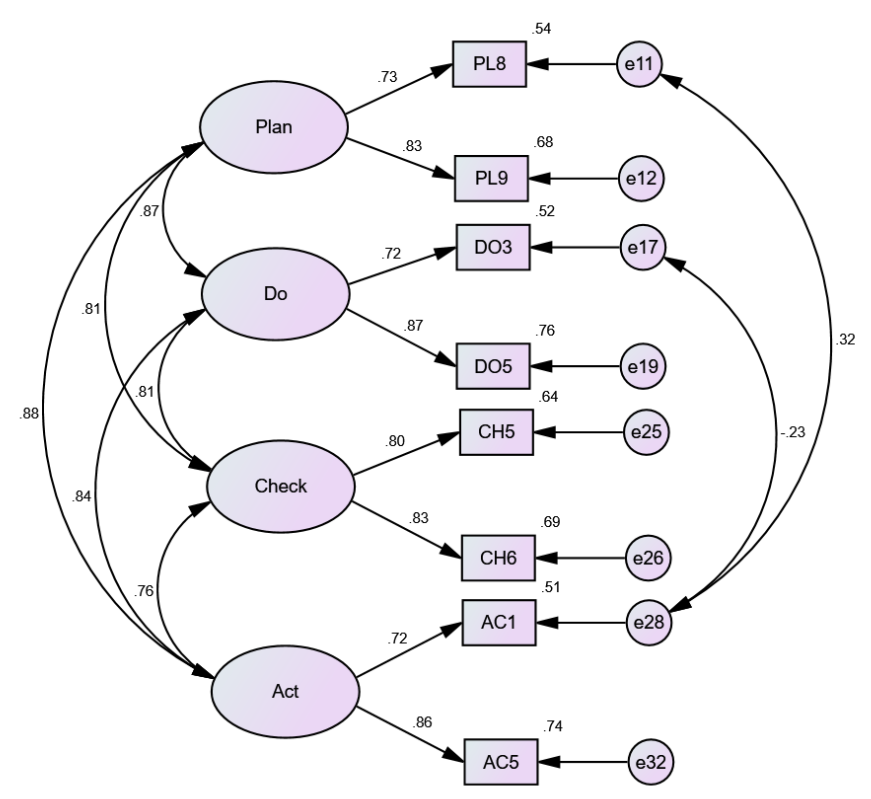

Fig. 2: Confirmative component analysis (CFA) results after model modification.

Figure 2 illustrates the results of the CFA to verify the structural validity of the gauge after component adjustment.

When considering the composition of the planning variables, it was found that there were two variables that were weighted to indicate all variables. In order of ranking from highest to lowest, there was total cost reduction planning (PL9) and well coordination planning (PL8) with component weights of 0.83 and 0.73 , respectively. When considering the implementation components of the plan (Do), it was found that there were two variables that were weighted in the identification of all variables, arranged in order of priority from most to least, included variables, such as, 'increase welfare to keep operating personnel safe' (DO5) and 'prepare a report on the amount of inventory accurately matching the amount of inventory' (DO3) with element weights of 0.87 and 0.72 , respectively. When considering the assessment component (Check) found that there were two variables that were weighted to indicate all variables, in order of priority from least to greatest, i.e. 'adequate storage of goods in the adequate numbers without the problem of insufficient sales and to meet the demand' (CH6) and 'warehouse space can support all inventory storage and timely distribution' (CH5) The weight of the components was 0.83 and 0.80 , respectively, and when considering the components of the improvement (Act), it was found that there were 2 variables that were weighted in the indication of all variables, arranged in order of priority from most to least, i.e. improvement, convenient storage of products for withdrawing - paying and accountability (AC5) and streamline workflow without any interruption (AC1) was observed with component weights of 0.86 and 0.72 , respectively.

The researcher then adjusted the composition and chose how to connect the arrow lines. It was the result of a Second Order Confirmatory Factor Analysis (S-CFA) to verify the structural validity of the gauge. After adjusting the composition, it was found that $\mathrm{p}=0.46, \mathrm{CMIN} / \mathrm{DF}=0.99, \mathrm{GFI}=0.99$ and RMSEA $=0.00$, indicating that the model was consistent with the empirical data as shown in Fig. 3.

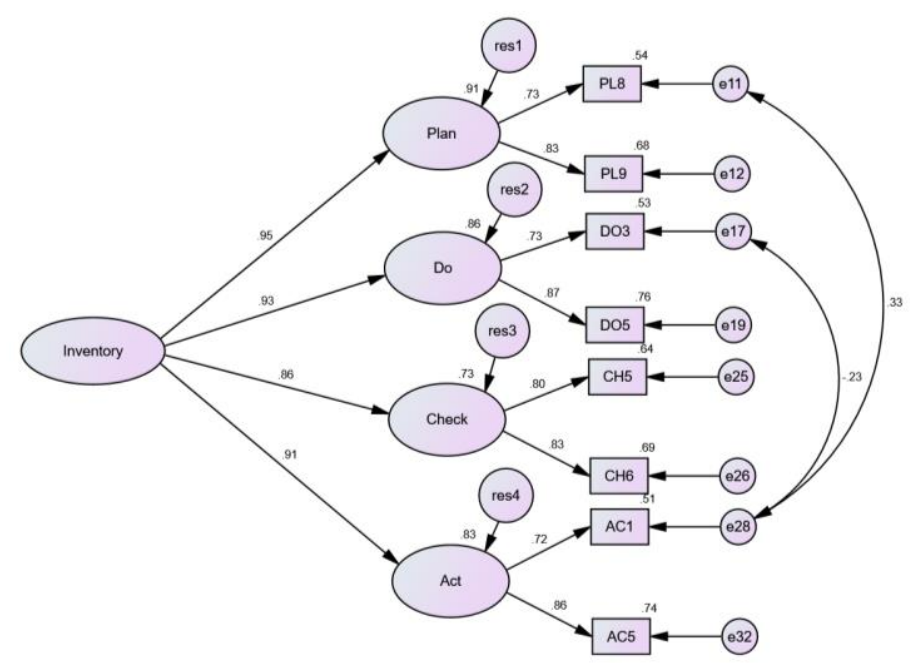

Fig. 3: The results of the second corroborative component analysis (S-CFA) after model tuning.

From Fig. 3, when considering the weights of each component, it was found that the component weights were positive $0.86-0.95$ with statistical significance at the 0.01 level. The first component, (Plan), had the highest component weight, equal to 0.95 , followed by implementation of the plan (Do) had an elemental weight of 0.93 , followed by improvement on (Act) has an elemental weight of 0.91 , and an evaluation (Check) has an elemental weight of 0.86, respectively. Each component had a measurement confidence (R2) of between 0.510.76 , indicating that all 4 components can be used as a component to optimize inventory management in the industrial sector. Thus, the confirmation component analysis of industrial inventory management optimization is consistent with the empirical data, thereby, showing that this model is 
structurally accurate because the model passes evaluation criteria that should be used (as shown in Table 2). Further, all 8 variables are important variables of the component of inventory management optimization in the industrial sector.

\section{Discussion}

1 ) The results of data analysis to examine the components of inventory management optimization in the industrial sector found that all 30 variables used in the analysis could be grouped into 4 components. From the elemental analysis by extracting the principal constituents and rotate the element axis with an acute angle by Varimax method with an eigen value greater than 1.00 . Each component consists of 6-1 1 variables have an element weight of 0.43-0.80. This adjusted element was given a title based on its character and purpose; corresponding and covering the list of variables in each component according to the Deming Cycle, with the weighted components in descending order: Plan, Do, Assessment (Check) and Improvement. The research was revised and was an extension of research hypothesis that used all 4 elements of the Deming cycle, for example: Research by Pothongsangarun and Kumplanon [22] that applied the Deming cycle as a model for the development of processes to optimize logistics management of the sugar industry in the Wangkanai factory; Research by Testa, Iraldo and Daddi [23] that summarized their research on the effectiveness of industrial environmental management tools in accordance with the ISO 14001 or EMAS (Eco Management and Audit Scheme) by applying all key elements of the Deming cycle which used to create a tool to store information that the organization had proved to perform better in terms of environment and yield higher incentives to invest in the environment It is a key factor highlighted in achieving real efficiency improvements. Research by Miranda and ReyesChua [24], explained that best practices in quality assurance in selected higher education institutions (HEIs) in the Philippines external quality audit framework starts and follows a process of quality management, implementation, review, and enhancement. Thus, is followed by the PDCA or Plan-do-check-act loop.

2) The results of the examination of the conformity between the constituent structure of industrial inventory management optimization and empirical data revealed that the confirmation element model, the confirmation element analysis of the industrial inventory management optimization, was significantly higher and consistent with empirical data. Similar to findings from the first and second corroborative component analysis results, it was found that the composition weight was positive. The first confirmed component weights were between $0.72-0.87$ and were statistically significant at the .01 level and the second confirmation component weight between $0.86-0.91$ was statistically significant at the .01 level, with the model-to-empirical harmonization index $\mathrm{p}=$ $0.46, \mathrm{CMIN} / \mathrm{DF}=0.99, \mathrm{GFI}=0.99$ and RMSEA $=0.00$. It shows that the confirmation component model, the confirmation component analysis of industrial inventory management optimization, is structurally accurate. And all 8 variables are important parameters of the component of inventory management optimization in the industry. The elements that have the weight in order from most to least are planning (Plan) with planning to reduce the overall cost and the need to have a good coordination plan, this is consistent with research by Goulielmos [25] that describes the importance of cost (cost) planning for shipping companies. This research focuses on using strategies to reduce transportation costs by analyzing the structure of different departments which related to the company's income and expenses. The result is reducing costs and unnecessary expenditure. and Vlasenko's research [26] has concluded the quality assurance control research that the in-house coordination of entrepreneurial activities is a modern concept to support effective entrepreneurial activities. It is also essential to understand that strategic control fulfills the function of implementing plans aligned with entrepreneurial goals. The main task is coordinating, strategic planning and control as well as providing information that is important to strategic decision-making, furthermore, operational controls will contribute to the planning process. Implementation of plans (Do) such as increasing welfare for employees. This is consistent with the research by Nagakumari and Pujitha [27], which states that employers provide benefits other than wages or salaries to employees. For example, welfare will help raise the standard of living of employees which create satisfaction for employees for efficiency and effectiveness can continue to achieve the goals of the organization. Assessment (Check) There 
is sufficient storage of products without problems such as insufficiency or excessive stocks, thereby meeting the needs of the customer and ensuring product distribution in a timely manner. This is in line with research by Lin [28], which said Wal-Mart's inventory management is an integral part of its internal control making it a successful company. If the inventory turnover rate and total asset turnover were adjusted, it could improve the economic efficiency of the business. The research by Fatehi and Franza [29] highlighted the importance of timely production, (Just-in-Time) and organizations should not ignore and be weary and careful to address and adopt the importance of timely production. Finally, the last component Modifications (Act) should improve the workflow to ensure a smooth process, without interruption of production and ensure smooth flow of finances. This is consistent with research by Susanto [30], which states that inventory control is an activity that helps organize the availability of goods to customers. The primary function of inventory is to ensure a smooth response to customer needs thus customer demand affects inventory levels. Many organizations face the problem of more inventories leading to increased costs. The research article of Gupta [31] highlighted the importance of effective inventory level management by developing an economic order quantity model (Economic Order Quantity: EOQ) to determine the appropriate amount of inventory for raw materials that can be stored in limited quantities.

\section{Suggestions}

\subsection{Suggestions for Applying the Research Results}

1 ) The results of the research resulted in a component to optimize inventory management in the industrial sector according to the composition of the Deming Cycle Therefore, the organization's executives can use this model to explore the organization by referring to the variables found in this study, to find strengths and weaknesses in the development of each variable.

2) The results of the research found that various issues in the industrial inventory management optimization component must receive complete support from corporate executives to ensure positive and accurate results.

\subsection{Suggestions for Future Research}

1 ) This research is a corroborative elemental analysis using Deming Cycle components. If there is a further research, the composition should be divided according to the ideas and theories of researchers or other scholars and be synthesized in order to obtain more comprehensive elements according to actual conditions

2)This research is a study of the industrial sector in Thailand only. Therefore, components of industrial inventory management optimization in other areas should be studied.

\section{References:}

[1] Marziali, M., Rossit, D. A., \& Toncovich, A. Warehouse Management Problem and a KPI Approach: a Case Study. Management and Production Engineering Review, 2021.

[2] Kondratjev, J. Logistics. Transportation and warehouse in supply chain, 2015.

[3] Rodprayoon, N., \& Chanasit, C. Study and development of inventory management system for frozen food business in Thailand. Modern Applied Science, 13(5), 2019, pp. 70-77.

[4] Schmidt, H. Explosive precursor safety: An application of the Deming Cycle for continuous improvement. Journal of Chemical Health \& Safety, 26(1), 2019, pp. 31-36.

[5] Deming, W. E. W. Edwards Deming. Madonna University, 1991.

[6] Moen, R., \& Norman, C. Evolution of the PDCA cycle, 2006.

[7] Johnson, C. N. The benefits of PDCA. Quality Progress, 49(1), 2016, p. 45.

[8] Atnafu, D., \& Balda, A. The impact of inventory management practice on firms' competitiveness and organizational performance: Empirical evidence from micro and small enterprises in Ethiopia. Cogent Business \& Management, 5(1), 2018, p. 1503219.

[9] Hançerlioğulları, G., Şen, A., \& Aktunç, E. A. Demand uncertainty and inventory turnover performance: An empirical analysis of the US retail industry. International Journal of Physical Distribution \& Logistics Management, 2016.

[10] Kesavan, S., Kushwaha, T., \& Gaur, V. Do high and low inventory turnover retailers respond differently to demand shocks?. Manufacturing \& Service Operations Management, 18(2), 2016, 198-215. 
[11] Jain, A., Mamani, H., \& Moinzadeh, K. Impact of retailers with knowledge of supplier's inventory on supply chain performance. Production and Operations Management, 26(3), 2017, pp. 542-556.

[12] Cholodowicz, E., \& Orlowski, P. Impact of Control System Structure and Performance of Inventory Goods Flow System with LongVariable Delay. Elektronika ir Elektrotechnika, 24(1), 2018, pp. 11-16.

[13] Manikas, A. Interdependence among inventory types and firm performance. Operations and Supply Chain Management: An International Journal, 10(2), 2017, pp. 63-80.

[14] Department of Industrial Works. Industrial statistics, 2020, Available at https://www.diw.go.th/webdiw/static-fac/, Access on 15 October 2021.

[15] Yamane, Taro. Statistics, An Introductory Analysis ( $2^{\text {nd }}$ ed). New York : Harper and Row, 1967.

[16] Joshi, A., Kale, S., Chandel, S. \& Pal, D.K. Likert scale: Explored and explained. British Journal of Applied Science \& Technology, 7(4), 2015, p. 396.

[17] Turner, R. C., \& Carlson. Index of Item Objective Congruence for Multiple Objective Measures. Unpublished manuscript, University of Arkansas, 2002.

[18] George, D., \& Mallery, P. SPSS for Windows step by step: A simple guide and reference. 11.0 update (4th ed.). Boston: Allyn \& Bacon, 2003.

[19] Tabachnick, B., \& Fidell, L. Using Multivariate Statistics. Boston, MA : Pearson Education Inc, 2013.

[20] Angsuchot, S. , Wichitwanna, S. \& Phinyophanuwat, R. Statistical analysis for research in social sciences and behavioral science: Techniques in using the LISREL program. Bangkok : Charoendi Mankhong Press, 2011.

[21] Arbuckle, J. L. IBM SPSS Amos 22 User's Guide. U.S.A. IBM Corporation, 2013.

[22] Pothongsangarun, T., \& Kumplanon, N. Efficiency Enhancing of Logistics Management for the Sugar Industry Group: Case Study of Wangkanai Sugar Factory Group. The Journal of KMUTNB, 27(2), 2017, pp. 371-378.

[23] Testa, F., Iraldo, F., \& Daddi, T. The effectiveness of EMAS as a management tool: A key role for the internalization of environmental practices. Organization \& Environment, 31(1), 2018, pp. 48-69.
[24] Miranda, R. D., \& Reyes-Chua, E. Best Practices in Quality Assurance in Selected Higher Education Institutions (HEIs) in the Philippines in the Light of the Malcolm Baldrige Framework. WSEAS Transactions on Environment and Development, 17, 2021, pp. 533-545.

[25] Goulielmos, A. M. Plan the Business of a Vessel of a Tramp Shipping Company. Modern Economy, 10(06), 2019, p. 1633.

[26] Vlasenko, V. A. Moskvitin E., Vlasenko V., Shved O., Ryzhova V., Goncharenco O. Controlling in quality assurance and internal coordination of entrepreneurship activity. Academy of Entrepreneurship Journal. 2020. Volume 26. Issue 3, 2021, pp. 1-7.

[27] Nagakumari, M. Y., \& Pujitha, M. C. N. Employee Welfare Measures in Manufacturing Industry, 2021.

[28] Lin, R. The importance of successful inventory management to enterprises: A case study of Wal-Mart. In 2019 International Conference on Management, Finance and Social Sciences Research (MFSSR 2019). London: Francis Academic Press, 2019.

[29] Fatehi, K., \& Franza, R. M. Systems considerations for adopting just-in-time production. Journal of Competitiveness Studies, 28(2), 2020, pp. 143-157.

[30] Susanto, R. Raw material inventory control analysis with economic order quantity method. In IOP Conference Series: Materials Science and Engineering (Vol. 407, No. 1, p. 012070). IOP Publishing, 2018.

[31] Gupta, R. Reconciling service levels by customers on a non-constrained production line for raw material and finished goods inventory levels, 2019.

\section{Creative Commons Attribution License 4.0 (Attribution 4.0 International, CC BY 4.0)}

This article is published under the terms of the Creative Commons Attribution License 4.0 https://creativecommons.org/licenses/by/4.0/deed.e n_US 